\title{
Doing Research with Young Children in Covid-19 Outbreak
}

\author{
Ridha Marissa El Seira ${ }^{1, *}$, Vina Adriany ${ }^{2}$,Euis Kurniati ${ }^{3}$ \\ ${ }^{1,2,3}$ Department of Early Childhood Education, School of Postgraduate, Universitas Pendidikan Indonesia. \\ *Corresponding author. Email: ridhamarissa@upi.edu
}

\begin{abstract}
This article aims to explore how the Covid-19 pandemic impacts early childhood research. The Covid-19 pandemic has a major impact on various aspects of early childhood life, including research on early childhood during the pandemic. This article also aims to explore the challenges that exist in early childhood research during the pandemic. Using a literature review, this article would explore the challenges of conducting early childhood research during the Covid-19 pandemic. The findings of this article are expected to offer recommendations for researchers and academics on how to conduct early childhood research during the pandemic.
\end{abstract}

Keywords: Early childhood, children, Covid-19, pandemic, research, researcher.

\section{INTRODUCTION}

The purpose of this research is to uncover the challenges that arise in making research about early childhood during the Covid-19 pandemic. It has been more than half a year since the Covid-19 pandemic was first announced as a pandemic by WHO [1]. The Covid19 pandemic not only affects the condition of the world economy, but Covid-19 also affects the lives of early childhood which is an asset for future generations. Research in early childhood such as health [2], mental health [3], education [4], and social [5] contributes to monitoring and ensuring the safety, rights, equality, and development of children as assets and the next generation in passing the Covid-19 pandemic. The existence of the Covid-19 pandemic phenomenon gave rise to many new elements in early childhood research, such as economic, social, and political issues that turned out to be hidden behind early childhood issues. Reveal new shortcomings that have yet to emerge, including enlarging the dimensions of inequality [8] which is seen in public health, social structures, and systems [9] around children.

Social distancing and home quarantine during the Covid-19 pandemic caused limited space to conduct research for researchers and participants. In the process of retrieving data for example, which initially needed to be done directly, changed to be done online [8], [4]. This can be an obstacle in conducting research in early childhood, so it is necessary to pay attention and make research plans very carefully. Research also needs to adjust to the ability of the participant's families, rather than complicating the family in research during the
Covid-19 pandemic. Difficulties that occur during the pandemic period cause stress and harm to the physical as well as the mental health of the child and parents which can cause higher rates of violence in children [10]. It also needs to be considered in conducting research. Researchers need to pay attention to the possibilities that have an impact on children when conducting research [11].

However, there are still limited studies that make research about early childhood research itself during the Covid-19 pandemic. With the number of issues that have emerged and changes in how the data are collected due to home quarantine during the pandemic, researchers need to deal with various things while conducting research with young children. It is our responsibility as researchers and academics to pay attention to the challenges that arise when conducting research on early childhood during the Covid-19 pandemic.

\section{CHALLENGES IN DOING RESEARCH DURING THE COVID-19 PANDEMIC}

Many challenges arise in conducting research on early childhood during the Covid-19 pandemic, including (a) limitations faced by researchers, (b) ethical issues that researchers need to consider, (c) children's rights including the involvement of children's voices in the research. 


\subsection{Limitations Faced by Researchers}

The number of issues that emerge during the Covid19 pandemic related to inequality, vulnerability, and other issues on the one hand makes its own advantages for researchers to be able to explore the number of issues that are revealed. However, during the Covid-19 pandemic, many studies were delayed due to the enactment of the lockdown or home quarantine system. This has an impact on the data collection process faced by the researchers. The existence of a lockdown system or home quarantine requires researchers to conduct online-based data collection [12] which not all researchers, nor participants have online access.

Lockdown or home quarantine also causes major changes in the economic system. This has an impact on the researchers as a challenge to get funding for their research. This creates pressure for researchers which causes stress [13]. Moreover, pressure and stress are the most prominent things in making research during the Covid-19 pandemic [14] that can impact many aspects of researchers' lives.

\subsection{Ethical Issue}

During the Covid-19 pandemic, data collection needs to be done online and still need to pay attention to ethical issues. Researchers need to take responsibility to keep children safe by avoiding face-to-face encounters [12] and ensuring to not harm children during the data collection. In the process, researchers need to pay attention to access to online data retrieval [12] either by facilitating or by replacing facility costs during online data retrieval. However, as a researcher, we need to give an explanation to the child about what the information to be collected is used in advance. They have the right to convey their opinion and make decisions whether or not to participate in research, and they may decide to quit whenever they want [15].

In preparing the research, researchers need to consider the cause and effect of the questions that will be given to the children so as not to make the child feel uncomfortable. We never know what happens during home quarantine, maybe home quarantine makes children's privacy reduce and cause trauma for the children [12]. Researchers need to draw up questions that don't remind the children about bad things or avoid things that might lead them to something traumatic.

Considering the child's consent is also crucial. Data collection will only be done willingly and without coercion before collecting data and information from children. Researchers need to ensure the security and confidentiality of children's data and information in the study [12], [16], [17]. However, as a researcher, we have to be careful with the power relations, because of children's position in society, and if so, it might be difficult for the research because sometimes adults are involved to make the decision, not truly the children's decision. Power relations are more problematic due to the position of children in society. It requires the use of methods that are suitable for children so that meaningful data is obtained in conducting research with children [18].

Furthermore, by the time the data collection has been completed, researchers should know that research data cannot be disseminated to anyone even at an institution. The findings are only used to support the needs of the child and in accordance with pre-planned research objectives [12]. This avoids misuse of data that could harm a particular group and increase inequality during the Covid-19 pandemic.

\subsection{Children's Right}

Research on children during the Covid-19 pandemic is quite complex, considering that research must be done by not face to face because of social distancing. Meanwhile, research on children should still contain children's voices. This is because we have to listen and respect every child's rights for their voice [19].

The desire to be able to protect children is very high, but children's voices and children's views during the pandemic are often overlooked. Whereas previous research on the SARS pandemic has shown that children's participatory decisions are an important consideration during pandemics [16], [17], [20]. The view of children in the pandemic period can be used as a reference to be a lesson in dealing with pandemics that may occur in the future.

Although children are very active to participate in research, there is still a lot of power relation in its application. Sometimes children feel uncomfortable with the questions given during the research. Sometimes children know what we want to hear so that they make a statement that we want to hear and not purely their views. In this case, we need to pay attention to holistically constructed communication through open dialogue, consultation, and respect for autonomy and children's view [21]. This is very important in research that tries to explore a child's view of something because children can control their contribution to the research [11].

As researchers and academics for the early childhood field, we need to make sure that children's voices appear in our research. Children need to be informed of all their information and their rights in advance. They also need to be informed that they can give their opinion and perhaps decide whether to join or leave the research whenever they want. Sometimes consent can be given by parents, so parents play an important role in a child's participation in research, but the child still needs to decide whether to participate in a study or not [22]. 
Work with children requires strategies and ways that require a lot of energy and skills to be able to build relationships and build trust with the children and the children's family [22]. Researchers are responsible to ensure child consent, safety, confidentiality, and comfort of children so as not to harm them [15].

During the pandemic, we can ask children to draw some images, make stories, build the conversation, or do role-playing, it will be very possible to be able to bring up the child's perspective. To ask the question, we can also include images in interviews as well as focus groups with children [15]. This can be done online by using the online platform app for collecting data and involving children so that we can listen to children's voices, it can be by call or video call to make the conversation like consulting. The consultation can be per each child or even project consultation with small groups of children where children can express what they have observed, what they heard, and what they experience during home quarantine. Before asking the questions, tell the children that there is no right or wrong answer, and if they don't have an answer, then it doesn't matter. We should not try to control what the children say, not interrupt them, and let them reveal what they are thinking because it is part of what the children have already experienced. Moreover, questions that ask direct questions about experiences of violence are not recommended during the pandemic [23].

In pandemic conditions, there will always be power relation imbalances due to the possibility of a power imbalance between adults and children. We need to be more flexible in the process of retrieving data, paying attention to the place, time, and sentences used when retrieving data with children. Setting conversations that are not informal can make children feel free to express their opinions. In this case, the researcher's perspective on building meaningful interactions, respecting children's participation and negotiation, and decision-making which is taken by children will be very important in the research [24], [25]. Children need to be given a forum and a means to express themselves, and researchers need to listen with them about what is communicated and reflect deeply on what their expressions mean [24]. In addition, researchers need to "place themselves" in the research and it is called reflexivity as a researcher. This means that the researchers tell their background maybe in their background paper or methodology, and then explain how that gives the colors and influence their interpretation of the data research, and what conclusions or results they derive from the research.

\section{CONCLUSION}

Covid-19 pandemic is a new phenomenon that can change various aspects in almost various parts of the world. Researchers experience many challenges, especially challenges in the process of data retrieval. Researchers also faced the fact that the existence of home quarantine not only inhibits the process of data retrieval but also affects stress levels.

However, in such conditions, researchers still need to pay attention to ethical issues of research during the Covid-19 pandemic. Researchers need to ensure the participation of children without coercion and with their permission, researchers also need to adapt to the use of the online base in data retrieval and still maintain the safety and privacy of children, as well as respect the opinions and decisions of children during the data retrieval process.

In addition, children's voice was a real challenge in conducting early childhood research during the Covid-19 pandemic. By involving children's voices, the novelty of research during the Covid-19 pandemic began to emerge. The need to pay attention to the code of ethics, child consent, involvement of children's voice, flexibility of researchers, and reflection of researchers are things that are likely to appear as a challenge in research. Many things that need to be prepared by researchers such as data retrieval strategies, types of questions, and setting activities which can make children more comfortable so as to build understanding and more findings in conducting early childhood research during the Covid-19 pandemic.

\section{ACKNOWLEDGMENT}

The acknowledgement would be given to Ministry of Education and Culture (Indonesia) for the research grant that support the completion of this research.

\section{REFERENCES}

[1] WHO. Coronavirus Disease 2019 [internet]. Available from: https://doi.org/10.1213/xaa.0000 000000001218 .

[2] Weiner DL, Balasubramaniam V, Shah SI, Javier JR. Pediatric policy council. covid-19 impact on research, lessons learned fromcovid-19 research, implications for pediatric research. Pediatric Research. 2020;88(2):148-50. DOI: 10.1038/s41390-020-1006-3.

[3] Singh S, Roy D, Sinha K, Parveen S, Sharma G, Joshi G. Impact of covid-19 and lockdown on mental health of children and adolescents: A narrative review with recommendations. Psychiatry Research. 2020;293:110. Available from: https://doi.org/10.1016/ j.psychres.2020.113429.

[4] Dong C, Cao S, Li H. Young children's online learning during covid-19 pandemic: Chinese parents' beliefs and attitudes. Children and Youth Services Review. 2020;118:1-10. DOI: 10.1016/j.childyouth.2020. 105440 .

[5] Settersten RA, et al. Understanding the effects of Covid-19 through a life course lens. Advance in Life 
Course Research. 2020;45:1-11. DOI: 10.1016/ j.alcr.2020.100360.

[6] Muroga A, Zaw HT, Mizunoya S, Lin HC, Brossard M, Reuge N. Covid-19: A reason to double down on investments in pre-primary education. 2020;11:1-22. Available from: https://www.un-ilibrary.org/content /papers/252067962020:1-22.

[7] Tisdell CA. Economic, social and political issues raised by the COVID-19 pandemic. Econ Anal Policy. 2020;68:17-28. DOI: 10.1016/j.eap.2020. 08.002 .

[8] Baginsky M, Manthorpe J. The impact of covid-19 on children's social care in England. Child Abuse \& Neglect. 2020;in press:1-10. DOI: 10.1016/ j.chiabu.2020.104739.

[9] Haffejee S, Levine DT. 'When will I be free': Lessons from COVID-19 for Child Protection in South Africa. Child Abuse \& Neglect. 2020 Dec 1;110(2):1-45. DOI: https://doi.org/10.1016/ j.chiabu.2020.104715

[10]Brown SM, Doom JR, Lechuga-Peña S, Watamura SE, Koppels T. Stress and parenting during the global COVID-19 pandemic. Child Abuse \& Neglect. 2020;110(2):1-14. DOI: 10.1016/j.chiabu. 2020.104699 .

[11] Neill SJ. Research with children: A critical review of the guidelines. Journal of Child Health Care. 2005;9(1):46-58. DOI: 10.1177/1367493505049 646.

[12]Berman G. Ethical considerations for evidence generation involving children on the covid-19 pandemic. 2020;1:1-18. Available from: https://www.unilibrary.org/content/papers/2521111 0 .

[13] Byrom N. COVID-19 and the Research Community: The challenges of lockdown for early-career researchers. Elife. 2020;9:1-3. DOI: 10.7554/ ELIFE.59634.

[14]Morgan C, Rose N. Multidisciplinary research priorities for the covid-19 pandemic. The Lancet Psychiatry. 2020; 7(7):e33. DOI: 10.1016/S22150366(20)30230-3.

[15]Curtin C. Eliciting children's voices in qualitative research. American Journal of Occupational Therapy. 2001 May 1;55(3):295-2. DOI: 10.5014/ajot.55.3.295.

[16] Mourad M, Bousleiman S, Wapner R, GyamfiBannerman C. Conducting research during the COVID-19 pandemic. In Seminars in Perinatology 2020 Nov 1;44(7): 1-4.

[17] Koller D, Nicholas D, Gearing R, Kalfa O. Paediatric pandemic planning: children's perspectives and recommendations. Health \& Social Care in the
Community. 2010;18(4):369-77. DOI: 10.1111/j.1365-2524.2009.00907.

[18]Kirk S. Methodological and ethical issues in conducting qualitative research with children and young people: A literature review. International Journal of Nursing Studies. 2007;44(7):1250-60. DOI: 10.1016/j.ijnurstu.2006.08.015.

[19] UNICEF. The United Nations Convention on the Rights of the Child. London. 2019:1-14. DOI: 10.1163/9789460913020_012.

[20] Koller DF, Nicholas DB, Goldie RS, Gearing R, Selkirk EK. When family-centered care is challenged by infectious disease: Pediatric health care delivery during the SARS outbreaks. Qualitative Health Research. 2006;16(1):47-60. DOI: $10.1177 / 1049732305284010$.

[21]Levine DT, Morton J, O'Reilly M. Child safety, protection, and safeguarding in the time of covid-19 in Great Britain. Proposing a conceptual framework. Child Abuse \& Neglect. 2020;110(2):1-9. DOI: 10.1016/j.chiabu.2020.104668.

[22] Moore T, McArthur M, Noble-Carr D. Little voices and big ideas: Lessons learned from children about research. International Journal of Qualitative Methods. 2008;7(2):77-91. DOI 10.1177/160940690800700205.

[23] Babvey P, Capela F, Cappa C, Lipizzi C, Petrowski N, Ramirez-Marquez J. Using social media data for assessing children's exposure to violence during the COVID-19 pandemic. Child Abuse \& Neglect. 2020:1-14. DOI: 10.1016/j.chiabu.2020.104747.

[24] Pascal C, Bertram T. Listening to young citizens: The struggle to make real a participatory paradigm in research with young children. European Early Childhood Education Research Journal. 2009;17(2):249-62.

DOI: 10.1080/13502930902951486.

[25] Tay-Lim J, Lim S. Privileging younger children's voices in research: Use of drawings and a coconstruction process. International Journal of Qualitative Methods. 2013;12(1):65-83. DOI: 10.1177/160940691301200135. 